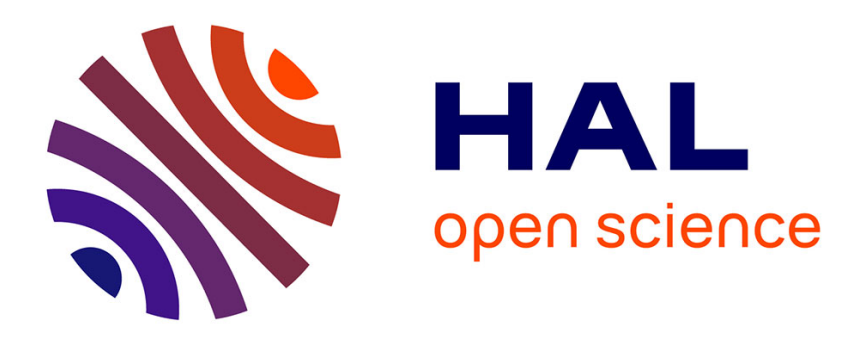

\title{
Crystal and electronic structure and magnetic properties of CeRhPb
}

\author{
L.D. Gulay, D. Kaczorowski, A. Szajek, A. Pietraszko
}

\section{To cite this version:}

L.D. Gulay, D. Kaczorowski, A. Szajek, A. Pietraszko. Crystal and electronic structure and magnetic properties of CeRhPb. Journal of Physics and Chemistry of Solids, 2009, 69 (8), pp.1934. 10.1016/j.jpcs.2008.01.020 . hal-00538004

\section{HAL Id: hal-00538004 https://hal.science/hal-00538004}

Submitted on 20 Nov 2010

HAL is a multi-disciplinary open access archive for the deposit and dissemination of scientific research documents, whether they are published or not. The documents may come from teaching and research institutions in France or abroad, or from public or private research centers.
L'archive ouverte pluridisciplinaire HAL, est destinée au dépôt et à la diffusion de documents scientifiques de niveau recherche, publiés ou non, émanant des établissements d'enseignement et de recherche français ou étrangers, des laboratoires publics ou privés. 


\section{Author's Accepted Manuscript}

Crystal and electronic structure and magnetic properties of $\mathrm{CeRhPb}$

L.D. Gulay, D. Kaczorowski, A. Szajek, A. Pietraszko

PII: $\quad$ S0022-3697(08)00046-2

DOI: $\quad$ doi:10.1016/j.jpcs.2008.01.020

Reference: $\quad$ PCS 5385

To appear in: Journal of Physics and

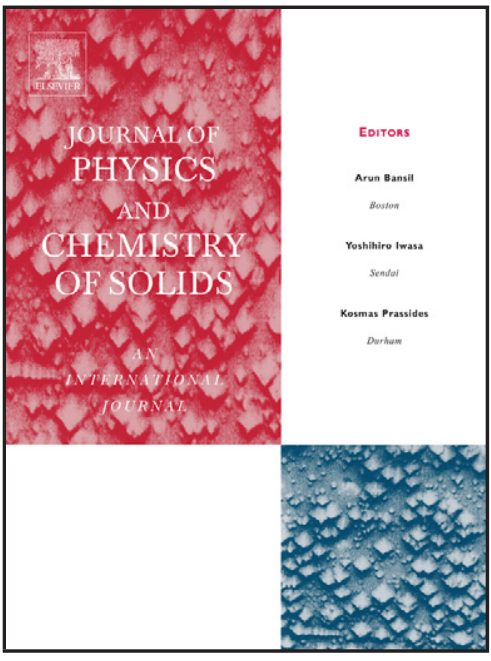

www.elsevier.com/locate/jpcs Chemistry of Solids

Received date: 25 October 2007

Revised date: 8 January 2008

Accepted date: $\quad 30$ January 2008

Cite this article as: L.D. Gulay, D. Kaczorowski, A. Szajek and A. Pietraszko, Crystal and electronic structure and magnetic properties of $\mathrm{CeRhPb}$, Journal of Physics and Chemistry of Solids (2008), doi:10.1016/j.jpcs.2008.01.020

This is a PDF file of an unedited manuscript that has been accepted for publication. As a service to our customers we are providing this early version of the manuscript. The manuscript will undergo copyediting, typesetting, and review of the resulting galley proof before it is published in its final citable form. Please note that during the production process errors may be discovered which could affect the content, and all legal disclaimers that apply to the journal pertain. 


\title{
Crystal and electronic structure and magnetic properties of $\mathrm{CeRhPb}$
}

\author{
L. D. Gulay ${ }^{1,2}$, D. Kaczorowski ${ }^{1, *}$, A. Szajek ${ }^{3}$, and A. Pietraszko ${ }^{1}$ \\ ${ }^{1}$ Institute of Low Temperature and Structure Research, Polish Academy of Sciences, \\ P. O. Box 1410, 50-950 Wroctaw, Poland \\ ${ }^{2}$ Department of Ecology and Protection of Environment, Volyn State University, \\ Voli Ave 13, 43009 Lutsk, Ukraine \\ ${ }^{3}$ Institute of Molecular Physics, Polish Academy of Sciences, \\ M. Smoluchowskiego 17, 60-179 Poznań, Poland
}

\begin{abstract}
The new intermetallic cerium compound $\mathrm{CeRhPb}$ was synthesised by arc melting and studied by means of X-ray diffraction and magnetic measurements. The crystal structure determined from the single crystal X-ray data is of the ZrNiAl type (space group $P \overline{6} 2 \mathrm{~m}$ ). The compound was found to be a Pauli paramagnet with $4 f^{\theta}$ ground state of the Ce atoms. The ab-initio band structure calculations performed without and with spin polarization confirmed nonmagnetic character of the plumbide studied.
\end{abstract}

Keywords: Ternary intermetallic plumbides; Crystal structure; Magnetic properties; Electronic structure calculations

${ }^{*}$ Corresponding author.

E-mail address: D.Kaczorowski@int.pan.wroc.pl (Dariusz Kaczorowski) 


\section{Introduction}

Rare-earth metal containing intermetallic compounds have been proven important from both a scientific and a technological point of view. In particular, intense studies of various binary and ternary cerium-based compounds have recently resulted in prominent discoveries of fascinating physical phenomena, like for example heavy-fermion superconductivity with exotic pairing mechanisms and unconventional symmetries, quantum criticality and non-Fermi liquid behaviors. For these reasons search for novel cerium intermetallics continues to be a central issue in modern material science.

The ternary system $\mathrm{Ce}-\mathrm{Rh}-\mathrm{Pb}$ has not been investigated until recently. The only ternary phase reported up to date was $\mathrm{Ce}_{2} \mathrm{Rh}_{2} \mathrm{~Pb}$, which crystallizes with a tetragonal crystal structure of the $\mathrm{Mo}_{2} \mathrm{FeB}_{2}$ type (space group $P 4 / \mathrm{mbm}$ ) [1]. The compound exhibits metallic conductivity with no hint at any magnetic phase transitions down to liquid helium temperature.

In this paper we report for the first time on the constitution a novel phase in this system, namely $\mathrm{CeRhPb}$. Its crystal structure was determined and refined from the single crystal X-ray data, and the magnetic properties were measured down to $1.72 \mathrm{~K}$. The experimental characterization is accompanied by the results of ab-initio calculations of the electronic band structure.

\section{Experimental details}

A polycrystalline sample with the nominal composition $\mathrm{CeRhPb}$ was prepared by arc melting the constituting elements of purity better than $99.9 \mathrm{wt} \%$ in high-purity Ti-gettered argon atmosphere. The button was remelted several times to ensure good homogeneity. The losses after melting were less than 1 wt. \%. No other heat treatment was applied.

The obtained sample was checked by X-ray powder diffraction using a Siemens D5000 powder diffractometer $\left(\mathrm{CuK}_{\alpha}\right.$ radiation, $10^{\circ} \leq 2 \theta \leq 100^{\circ}$, step scan mode with a step size of $0.02^{\circ}$ and counting time of 37 seconds per data point). The X-ray pattern was indexed within hexagonal symmetry with the lattice parameters $a=0.76627(2) \mathrm{nm}$ and $c=0.40237(2) \mathrm{nm}$, as determined by least-squares method using the CSD program [2].

A small single crystal of $\mathrm{CeRhPb}$, suitable for the crystal structure determination was selected from the crushed polycrystalline ingot. The X-ray data were collected on a KUMA Diffraction KM-4 four-circle diffractometer equipped with a CCD camera using graphite-monochromatized $\mathrm{MoK}_{\alpha}$ radiation $(\lambda=0.071073 \mathrm{~nm})$. Intensities of the reflections were corrected for Lorentz and polarisation 
factors, and a semiempirical absorption correction was applied. The crystal structure was solved by the Patterson method [3] and refined by full-matrix least-squares using the SHELX-97 program [4].

Magnetic measurements were performed in the temperature range 1.72-400 $\mathrm{K}$ and in applied magnetic fields up to $5 \mathrm{~T}$ using a Quantum Design MPMS-5 SQUID magnetometer.

\section{Calculations method}

The electronic structure of $\mathrm{CeRhPb}$ was studied by means of the full-potential local-orbital (FPLO) method [5] based on the local spin density approximation (LSDA) [6]. The calculations were performed with and without spin polarization. The experimental values of the lattice parameters, as refined from the X-ray single crystal data, were used. The computational method assumes different treatment of electrons, i.e. their orbitals may be classified according to the spatial extend of the radial functions and according to their occupation [5]. The electronic configurations of atoms used in the calculations were the following: core + valence electrons $(4 f 5 s 5 p 6 s 6 p 5 d)$ for Ce atoms, core + semicore electrons $(4 s 4 p)+$ valence electrons $(5 s 5 p 4 d)$ for Rh atoms, and core + semicore $(5 s 5 p)+$ valence electrons $(6 s 6 p 5 d)$ for $\mathrm{Pb}$ atoms.

The calculations were performed for a reciprocal space mesh containing 2175 points within the irreducible wedge of the Brillouin zone using the tetrahedron method [7] for integrations. The LSDA exchange-correlation potential was assumed in the form proposed by Perdew and Wang [8]. The self consistent criterion was equal to $10^{-8}$ Ry for the total energy.

\section{Results and discussion}

\subsection{Crystal structure}

No systematic extinctions were observed in the X-ray intensities, in agreement with the space group $P \overline{6} 2 m$, which was then applied in the crystal structure refinement. Details on the structure refinement are summarized in Table 1, and Table 2 gathers the information on the atomic coordinates and the thermal displacement parameters. The compound was found to crystallize with the hexagonal ZrNiAl-type structure [9] with full occupancies of all the atomic sites. The lattice parameters refined from the single-crystal X-ray data are: $a=0.7671(1) \mathrm{nm}$ and $c=0.40274(7) \mathrm{nm}$, being very close to those derived from the powder X-ray pattern. 
The crystal structure of $\mathrm{CeRbPb}$ is shown in Fig. 1, together with the coordination polyhedra of all the atoms. The Ce atoms are located inside pentagonal prisms with seven additional atoms (c.n. $=$ 17). The neighbors of the $\mathrm{Pb}$ atoms form distorted cubooctahedra (c.n. = 12). In turn, the coordination spheres of the Rh1 and Rh2 atoms have a shape of trigonal prisms with three additional atoms (c.n. $=$ 9). As it is apparent from Fig. 2, these prisms constitute columns along the $z$ axis. The Rh2-centered trigonal prisms form circles of six prisms, while the Rh1-centered trigonal prisms are located in these circles.

The shortest interatomic distances in the unit cell of $\mathrm{CeRhPb}$ are collected in Table 3 , and compared there with the sums of the respective atomic radii $\Sigma_{r}$ (the latter values were taken from Ref. 10). The $\mathrm{Ce}-\mathrm{Pb}$ and $\mathrm{Rh}-\mathrm{Pb}$ interatomic distances are significantly shorter than $\Sigma_{r}$, thus indicating strong bonding. All the other interatomic distances are close to or longer than the sum of the atomic radii of the respective atoms.

\subsection{Magnetic properties}

The temperature dependence of the molar magnetic susceptibility of $\mathrm{CeRhPb}$ is presented in Fig. 3. Apparently, the compound is a Pauli paramagnet with the intrinsic susceptibility of the order of $2 \times 10^{-3} \mathrm{emu} / \mathrm{mol}$. Some temperature variation of $\chi_{\mathrm{m}}(T)$ should be attributed to the presence in the sample measured of spurious $\mathrm{Ce}^{3+}$ ions, presumably in the form of oxide layers on the specimen surface and grain boundaries ( $\mathrm{CeRhPb}$ as most of rare-earth plumbides easily oxidizes in air). The solid line in Fig. 3 is a least-squares fit of the experimental data in the entire temperature range to the formula:

$$
\chi_{m}(T)=\chi_{T I P}+\frac{n C}{T-\theta}
$$

where $\chi_{\text {TIP }}$ is the Pauli susceptibility of $\mathrm{CeRhPb}$, while the second term accounts for the contribution of $n \mathrm{Ce}^{3+}$ impurity ions, each characterized by the effective magnetic moment $\mu_{\text {eff }}=\sqrt{8 C}=2.54 \mu_{B}$ and the paramagnetic Curie temperature $\theta$. The so-derived parameters are $\chi_{\mathrm{TIP}}=2.1610^{-3} \mathrm{emu} / \mathrm{mol}, n=$ 0.078 atoms per formula unit and $\theta=-2.5 \mathrm{~K}$.

The magnetization measured at $1.72 \mathrm{~K}$ as a function of magnetic field (see the inset to Fig. 3) exhibits a typical paramagnetic behavior and proves the absence of any ferromagnetic impurities in the sample studied. 


\subsection{Electronic structure}

The results of band structure ab-initio calculations for the spin non-polarized case are displayed in Fig. 4. The left-side panel presents the total and site-projected densities of electronic states (DOS), and the right panel shows the partial $l$-decomposed DOS plots. In the total DOS a few characteristic features are notable. The valence band from about $-5 \mathrm{eV}$ to the Fermi level (taken as $E_{\mathrm{F}}=0$ ) is dominated by contributions from $d$-electrons, mainly from the $\mathrm{Rh}$ atoms located at the $1 b$ and $2 c$ sites. Also appreciable contributions to this region of the valence band come from the $\mathrm{Pb} p$-electrons, $\mathrm{Ce} d$ and $s$-electrons. The unoccupied part of DOS above $\mathrm{E}_{\mathrm{F}}$ consists of a band ( $\sim 1 \mathrm{eV}$ of width) due to the $4 f$ electrons from the $\mathrm{Ce}$ atoms with a signature of spin-orbit splitting and quite substantial contributions from the $\mathrm{Rh} d$-electrons. The number of $4 f$ electrons located on the Ce atoms is equal to 1.19. A gap of the order of $3 \mathrm{eV}$ separates the main valence band from weakly pronounced contributions coming essentially from the $\mathrm{Pb} s$-electrons. Between 15 and $20 \mathrm{eV}$ below the Fermi level four peaks are observed. These peaks show some structures and they are formed mainly by the Ce $5 p$ and $\mathrm{Pb} 5 d$ electrons with very small contributions of other types of electrons due to hybridization. The value of DOS at the Fermi level is 4.92 states/(eV f.u.) with the main contribution provided by the $4 f$ electrons (about $88 \%$ ). The contributions of other types of electrons and particular atoms are collected in Table 4. The calculated Sommerfeld coefficient in the linear term of the heat capacity amounts to 12 $\mathrm{mJ} /\left(\mathrm{mol} \mathrm{K}^{2}\right)$.

The calculations were also performed using spin polarization with initial band splitting giving starting spin magnetic moments equal to $0.5 \mu_{\mathrm{B}} / \mathrm{Ce}$ atom. The final self-consistent magnetic moment on the $\mathrm{Ce}$ atom was about $0.03 \mu_{\mathrm{B}}$ per atom. From these results one can conclude that within computational errors $\mathrm{CeRhPb}$ is nonmagnetic.

\section{Conclusions}

The new compound $\mathrm{CeRhPb}$ crystallizes in the hexagonal structure of the $\mathrm{ZrNiAl}$ type (space group $P \overline{6} 2 m)$, with the same atomic arrangement as reported before for the series $R \mathrm{PdPb}(R=\mathrm{Y}, \mathrm{La}$, $\mathrm{Ce}, \mathrm{Pr}, \mathrm{Nd}, \mathrm{Sm}, \mathrm{Gd}, \mathrm{Tb}, \mathrm{Dy}, \mathrm{Ho}, \mathrm{Er}, \mathrm{Yb}$ and $\mathrm{Ca}$ ) [11,12] and for the low-temperature modification of $\mathrm{LuNiPb}[13]$, i.e. the rare earth atoms are at the $3 g$ sites, the transition metal atoms reside at the $1 b$ and $2 c$ sites, and the $\mathrm{Pb}$ atoms are at the $3 f$ sites. Interestingly, in the unit cells of the $R \mathrm{AgPb}(R=\mathrm{Y}, \mathrm{Er}$, $\mathrm{Tm}, \mathrm{Lu}$ ) compounds, which form with the same structure type as $\mathrm{CeRhPb}$, the positions of the $\mathrm{Ag}$ and 
$\mathrm{Pb}$ atoms are switched, i.e. the former atoms are at the $3 f$ sites and the latter ones at the $1 b$ and $2 c$ sites [14]. This effect is clearly a consequence of differences in the atomic radii [15].

The compound $\mathrm{CeRhPb}$ is another representative of the family of equiatomic $\mathrm{Ce} T \mathrm{~Pb}$ plumbides which comprises also the phases with $\mathrm{T}=\mathrm{Cu}, \mathrm{Pd}, \mathrm{Ag}, \mathrm{Pt}$ and $\mathrm{Au}$ [16]. Hexagonal unit cells of the space group $P \overline{6} 2 m$ were reported for $\mathrm{CePdPb}$ [16] and $\mathrm{CePtPb}$ [17], however for none of them crystal structure determination has been performed up to date, so the exact atomic positions are unknown. The other $\mathrm{Ce} \mathrm{TPb}$ plumbides, i.e. $\mathrm{CeCuPb}, \mathrm{CeAgPb}$ and $\mathrm{CeAuPb}$, crystallize with a hexagonal structure of the space group $\mathrm{P}_{3} m c$ (NdPtSb-type) [16]. Regardless the crystal structure, all these ternaries exhibit strongly temperature dependent magnetism due to the presence of stable $\mathrm{Ce}^{3+}$ ions and order antiferromagnetically at low temperatures (possible yet unlikely exception may be $\mathrm{CePdPb}$ ) [16-18].

In contrast, as revealed from the magnetic studies, the cerium atoms in $\mathrm{CeRhPb}$ have a nonmagnetic $4 f^{\theta}$ ground state, which manifests itself in the temperature independent paramagnetic behavior. In agreement with the experimental data, the electronic structure calculations yielded for this compound a nonmagnetic ground state with relatively small density of states at the Fermi level due to $4 f$ electrons. The obtained electronic structure is somewhat similar to those derived previously for isostructural cerium intermetallics CeNiIn [19] and CeRhSn $[20,21]$. In the latter compounds, however, the $4 f$ contribution near $E_{\mathrm{F}}$ has been found considerably larger than that revealed for $\mathrm{CeRhPb}$, and consequently both phases exhibit valence fluctuation behavior instead of Pauli paramagnetism.

\section{Acknowledgement}

This work was supported by the National Scientific Network "Materials with strongly correlated electrons: manufacturing, research and applications" (MSSE). 


\section{References}

[1] A.M. Strydom, J. Alloys Compd. 394 (2005) 152.

[2] L.G. Aksel'rud, Yu.N. Grin', P.Yu. Zavalij, V.K. Pecharsky, and V.S. Fundamensky, Collected Abstr. 12th Eur. Crystallographic Meet., Moscow, August, 1989, Vol. 3, Izv. Acad. Nauk SSSR, Moscow, 1989, p. 155.

[3] G.M. Sheldrick, Program for the Solution of Crystal Structures, University of Göttingem, Germany, 1985.

[4] G.M. Sheldrick, Program for Crystal Structures Refinement, University of Göttingem, Germany, 1997.

[5] FPLO-5.00-18 [improved version of the original FPLO code by K. Koepernik and H. Eschrig, Phys. Rev. B 59 (1999) 1743]; http://www.FPLO.de.

[6] H. Eschrig, The Fundamentals of Density Functional Theory, 2nd Edition, Leipzig, 2003.

[7] P. Blöchl, O. Jepsen, O.K. Andersen, Phys. Rev. B 49 (1994) 16223.

[8] J.P. Perdew and Y. Wang, Phys. Rev. B 45 (1992) 13244.

[9] P.I. Kripyakevich, V.Ya. Markiv, E'.V. Mel'nyk, Dopov. Akad. Nauk Ukr. RSR 8A (1967) 750.

[10] G.B. Bokij, Kristallokhimija, Nauka, Moskwa, 1971.

[11] A. Iandelli, J. Alloys Compd. 203 (1994) 137.

[12] R. Marazza, D. Mazzone, P. Riani, G. Zanicchi, J. Alloy Compd. 220 (1995) 241.

[13] L.D. Gulay, J. Alloys Compd., in press.

[14] L.D. Gulay, J. Alloys Compd. 314 (2001) 219.

[15] E. Parthè, L. Gelato, B. Chabot, M. Penzo, K. Cenzual, R. Gladyshevskii, TYPIX-Standarized Data and Crystal Chemical Caracterization of Inorganic Structure Types, Gmelin Handbook of Inorganic and Organometallic Chemistry, $8^{\text {th }}$ edition, Springer, Berlin, 1993.

[16] W. Hermes, S. Rayaprol, R. Pöttgen, Z. Naturforsch. 62b (2007) 901, and the references cited therein.

[17] R. Movshovich, J.M. Lawrence, M.F. Hundley, J. Neumeier, J.D. Thompson, A. Lacerda, Z. Fisk, Phys. Rev. B 53 (1996) 5465.

[18] S.K. Dhar, P. Manfrinetti, A. Palenzona, Phys. Rev. B 51 (1995) 12464.

[19] S.F. Matar, B. Chevalier, V. Eyert, J. Etourneau, Solid State Sci. 5 (2003) 1385.

[20] T. Schmidt, D. Johrendt, C. P. Sebastian, R. Pöttgen, K. Łątka, and R. Kmieć, Z. Naturforsch. 60b (2005) 1036. 
[21] A. Ślebarski, M. Radłowska, T. Zawada, M.B. Maple, A. Jezierski, A. Zygmunt, Phys. Rev. B 66 (2002) 104434. 
Table 1. The crystal data and details on the structure refinement for $\mathrm{CeRhPb}$.

\begin{tabular}{|c|c|}
\hline Empirical formula & $\mathrm{CeRhPb}$ \\
\hline Formula weight & 450.22 \\
\hline Space group & $P \overline{6} 2 m$ (No. 189) \\
\hline \multirow[t]{2}{*}{ Unit cell dimensions } & $a=0.7671(1) \mathrm{nm}$ \\
\hline & $c=0.40274(7) \mathrm{nm}$ \\
\hline Volume & $0.20524(5) \mathrm{nm}^{3}$ \\
\hline Number of formula units per unit cell & 3 \\
\hline Calculated density & $10.93 \mathrm{~g} / \mathrm{cm}^{3}$ \\
\hline Absorption coefficient & $83.3 \mathrm{~mm}^{-1}$ \\
\hline$F(000)$ & 555 \\
\hline$\theta$ range for data collection & $3.07-28.92$ \\
\hline Index ranges & $-10 \leq h \leq 10$ \\
\hline & $-9 \leq k \leq 10$ \\
\hline & $-5 \leq l \leq 5$ \\
\hline Reflections collected & $23510-$ \\
\hline Independent reflections & $731[R($ int. $)=0.1045]$ \\
\hline Refinement method & Full-matrix least-square on $F^{2}$ \\
\hline Absolute structure parameter & $-0.02(1)$ \\
\hline Data/restraints/parameters & $230 / 0 / 14$ \\
\hline Goodness-of-fit on $F^{2}$ & 1.164 \\
\hline Final $R$ indices $[I>2 \sigma(I)]$ & $R 1=0.0250, w R 2=0.0495$ \\
\hline$R$ indices (all data) & $R 1=0.0260, w R 2=0.0498$ \\
\hline Extinction coefficient & $0.0028(6)$ \\
\hline Largest diff. peak and hole $\times 10^{-3}$ & 1.21 and $-1.43 \mathrm{e} / \mathrm{nm}^{3}$ \\
\hline
\end{tabular}




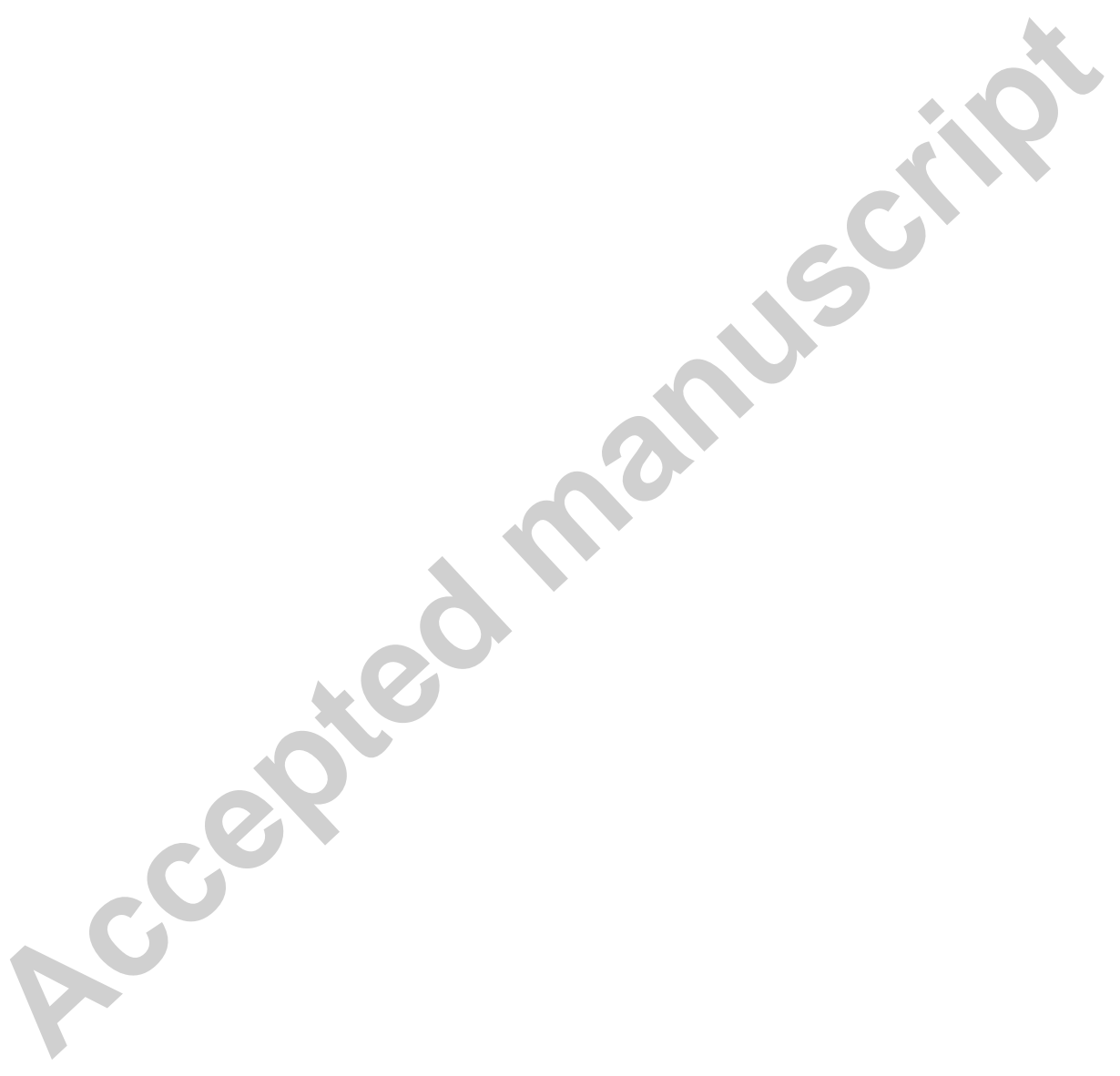




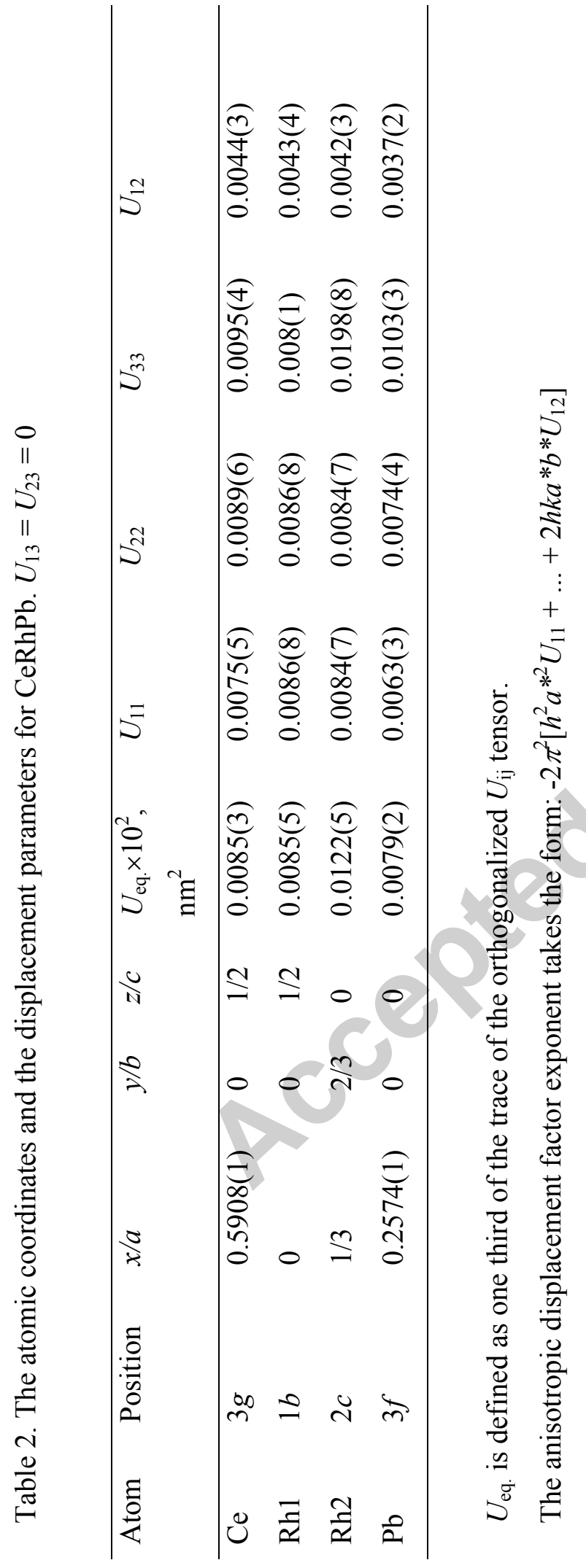


Table 3. The interatomic distances $(\delta, \mathrm{nm})$, the $\Delta$ values $\left(\Delta=100\left(\delta-\Sigma_{r}\right) / \Sigma_{r} ; \Sigma_{r}\right.$ is the sum of the respective atomic radii) and the coordination numbers (c.n.) of all the atoms in the unit cell of $\mathrm{CeRhPb}$.

\begin{tabular}{|c|c|c|c|c|}
\hline \multicolumn{2}{|l|}{ Atoms } & \multirow{2}{*}{$\begin{array}{l}\delta, \mathrm{nm} \\
0.30732(5)\end{array}$} & \multirow{2}{*}{$\begin{array}{l}\Delta \\
-3.05\end{array}$} & \multirow{2}{*}{$\frac{\text { c.n. }}{17}$} \\
\hline $\mathrm{Ce}$ & $-4 \mathrm{Rh} 2$ & & & \\
\hline & - 1Rh1 & $0.3138(1)$ & -1.01 & \\
\hline & $-2 \mathrm{~Pb}$ & $0.3255(1)$ & -9.08 & \\
\hline & $-4 \mathrm{~Pb}$ & $0.34070(9)$ & -4.83 & \\
\hline & $-4 \mathrm{Ce}$ & $0.40209(9)$ & +9.86 & \\
\hline & $-2 \mathrm{Ce}$ & $0.40274(7)$ & +10.04 & \\
\hline \multirow[t]{2}{*}{ Rh1 } & $-6 \mathrm{~Pb}$ & $0.28206(6)$ & -8.71 & \\
\hline & $-3 \mathrm{Ce}$ & $0.3138(1)$ & -1.01 & \\
\hline \multirow[t]{2}{*}{$\mathrm{Rh} 2$} & $-3 \mathrm{~Pb}$ & $0.28923(6)$ & -6.39 & 9 \\
\hline & $-6 \mathrm{Ce}$ & $0.30732(5)$ & -3.05 & \\
\hline \multirow[t]{5}{*}{$\mathrm{Pb}$} & $-2 \mathrm{Rh} 1$ & $0.28206(6)$ & -8.71 & 12 \\
\hline & $-2 R h 2$ & $0.28923(7)$ & -6.39 & \\
\hline & $-2 \mathrm{Ce}$ & $0.3255(1)$ & -9.08 & \\
\hline & $-4 \mathrm{Ce}$ & $0.34070(9)$ & -4.83 & \\
\hline & $-2 \mathrm{~Pb}$ & $0.3420(1)$ & -2.28 & \\
\hline
\end{tabular}


Table 4. The total, partial, and local DOS at the Fermi level in CeRhPb [in states/(eV (atom or f.u.))].

\begin{tabular}{lc|cc}
\hline Type of DOS & $\begin{array}{c}\text { Total and } \\
\text { l-decomposed } \\
\text { DOS (per f.u.) }\end{array}$ & $\begin{array}{c}\text { Atom } \\
\text { (position) }\end{array}$ & $\begin{array}{c}\text { Site-projected DOS } \\
\text { (per atom) }\end{array}$ \\
\hline Total & 4.92 & $\mathrm{Ce}(3 \mathrm{~g})$ & 4.67 \\
Total for $s$ electrons & 0.06 & $\mathrm{Rh}(1 \mathrm{~b})$ & 0.17 \\
Total for $p$ electrons & 0.15 & $\mathrm{Rh}(2 \mathrm{c})$ & 0.19 \\
Total for $d$ electrons & 0.36 & $\mathrm{~Pb}(3 \mathrm{f})$ & 0.07 \\
& & & \\
Total for $f$ electrons & 4.35 &
\end{tabular}




\section{Figure captions}

Fig. 1. The hexagonal unit cell of $\mathrm{CeRhPb}$ and the coordination polyhedra of the $\mathrm{Ce}(\mathrm{a}), \mathrm{Rh} 1(\mathrm{~b}), \mathrm{Rh} 2$ (c) and $\mathrm{Pb}(\mathrm{d})$ atoms.

Fig. 2. The Rh1- and Rh2-centered trigonal prisms in the crystal structure of $\mathrm{CeRhPb}$.

Fig. 3. The temperature variation of the molar magnetic susceptibility of $\mathrm{CeRhPb}$, measured in a field of $0.1 \mathrm{~T}$. The solid line is a fit described in the text. The inset shows the field variation of the magnetization in $\mathrm{CeRhPb}$ taken at $1.72 \mathrm{~K}$ with increasing (full circles) and decreasing (open circles) magnetic field strength.

Fig. 4. The total density of states (per f.u.) and the site contributions for DOS (per atom) (left panel), and the partial DOS (per f.u.) (right panel) in CeRhPb. The inset shows the contribution to the DOS near the Fermi level provided by the cerium $4 f$ electrons. 
Table 1. The crystal data and details on the structure refinement for $\mathrm{CeRhPb}$.

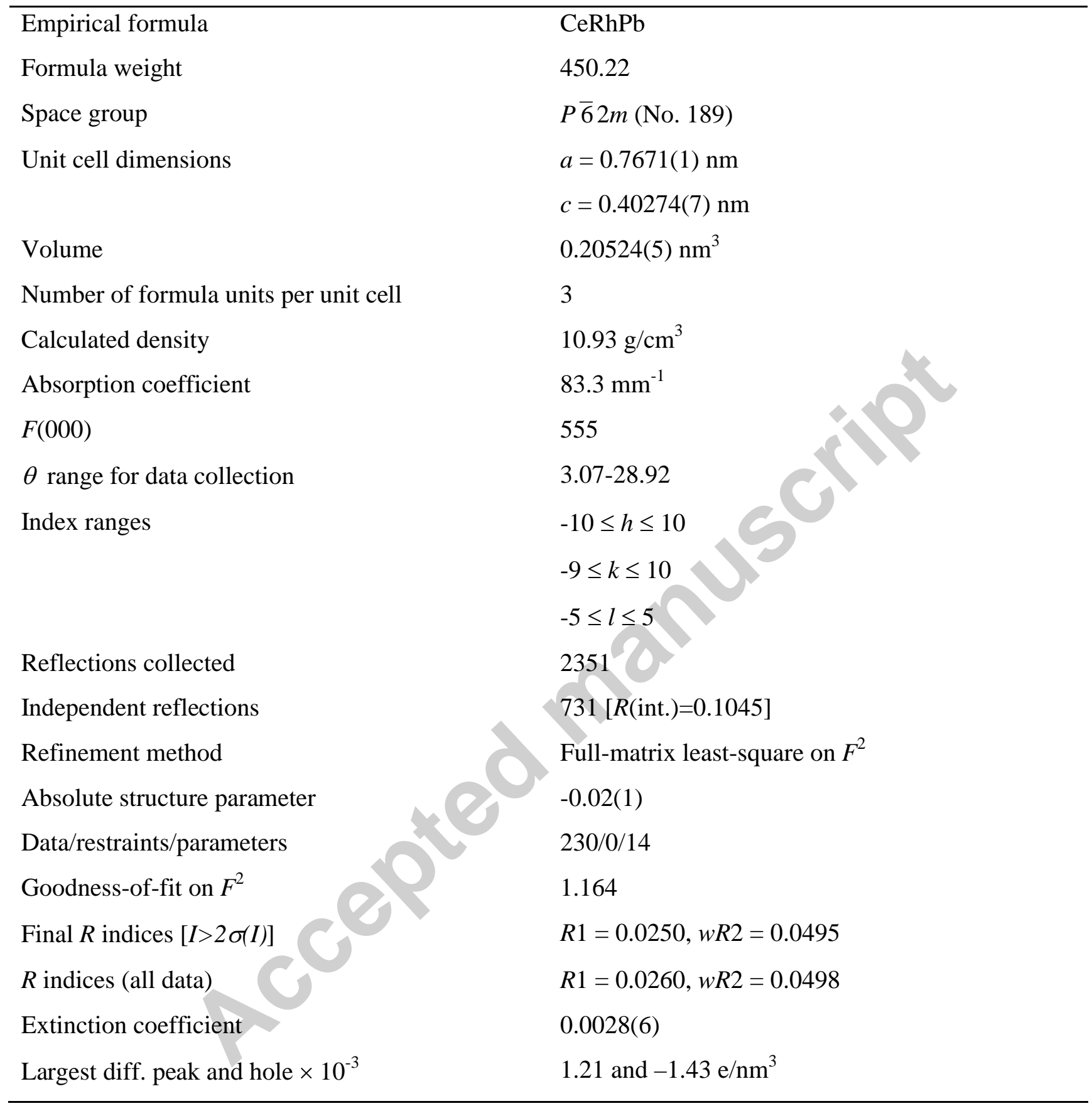




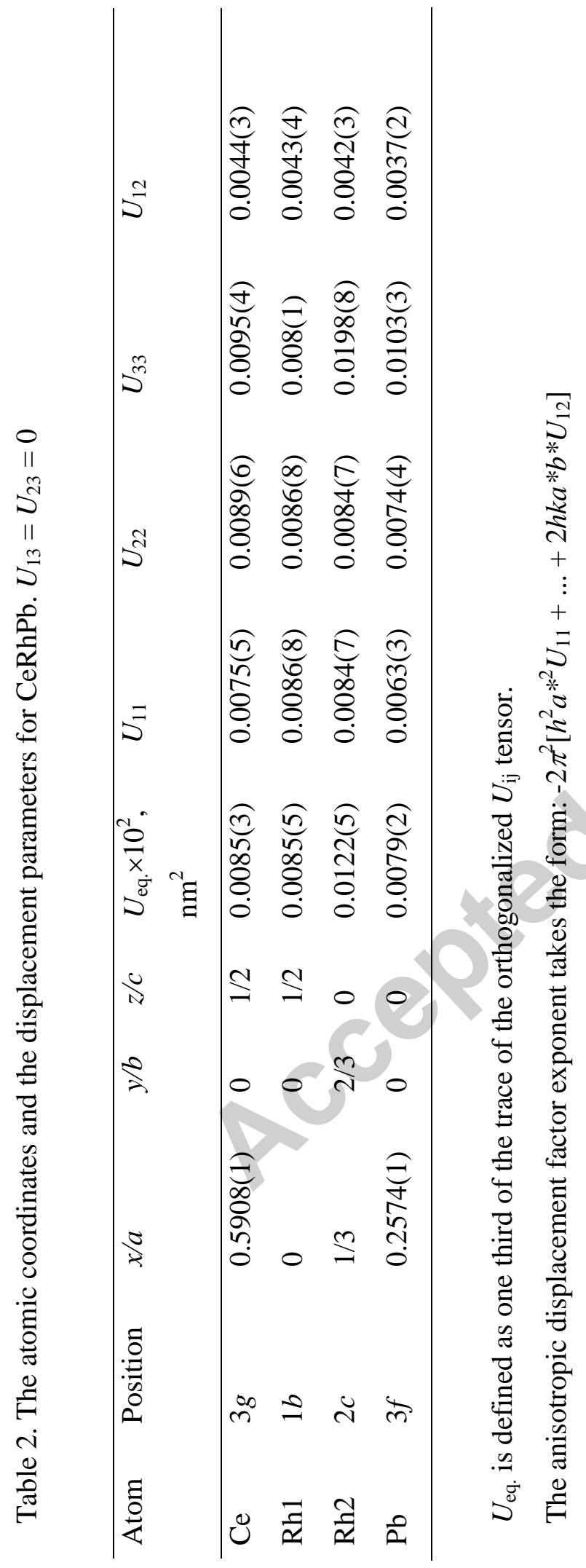


Table 3. The interatomic distances $(\delta, \mathrm{nm})$, the $\Delta$ values $\left(\Delta=100\left(\delta-\Sigma_{r}\right) / \Sigma_{r} ; \Sigma_{r}\right.$ is the sum of the respective atomic radii) and the coordination numbers (c.n.) of all the atoms in the unit cell of $\mathrm{CeRhPb}$.

\begin{tabular}{|c|c|c|c|c|}
\hline Atoms & & $\delta, \mathrm{nm}$ & $\Delta$ & c.n. \\
\hline $\mathrm{Ce}$ & $-4 \mathrm{Rh} 2$ & $0.30732(5)$ & -3.05 & 17 \\
\hline & - 1Rh1 & $0.3138(1)$ & -1.01 & \\
\hline & $-2 \mathrm{~Pb}$ & $0.3255(1)$ & -9.08 & \\
\hline & $-4 \mathrm{~Pb}$ & $0.34070(9)$ & -4.83 & \\
\hline & $-4 \mathrm{Ce}$ & $0.40209(9)$ & +9.86 & \\
\hline & $-2 \mathrm{Ce}$ & $0.40274(7)$ & +10.04 & \\
\hline Rh1 & $-6 \mathrm{~Pb}$ & $0.28206(6)$ & -8.71 & \\
\hline & $-3 \mathrm{Ce}$ & $0.3138(1)$ & -1.01 & \\
\hline Rh2 & $-3 \mathrm{~Pb}$ & $0.28923(6)$ & -6.39 & 9 \\
\hline & $-6 \mathrm{Ce}$ & $0.30732(5)$ & -3.05 & \\
\hline $\mathrm{Pb}$ & $-2 \mathrm{Rh} 1$ & $0.28206(6)$ & -8.71 & 12 \\
\hline & $-2 \mathrm{Rh} 2$ & $0.28923(7)$ & -6.39 & \\
\hline & $-2 \mathrm{Ce}$ & $0.3255(1)$ & -9.08 & \\
\hline & $-4 \mathrm{Ce}$ & $0.34070(9)$ & -4.83 & \\
\hline & $-2 \mathrm{~Pb}$ & $0.3420(1)$ & -2.28 & \\
\hline
\end{tabular}


Table 4. The total, partial, and local DOS at the Fermi level in CeRhPb [in states/(eV (atom or f.u.))].

\begin{tabular}{lc|cc}
\hline Type of DOS & $\begin{array}{c}\text { Total and } \\
\text { 1-decomposed } \\
\text { DOS (per f.u.) }\end{array}$ & $\begin{array}{c}\text { Atom } \\
\text { (position) }\end{array}$ & $\begin{array}{c}\text { Site-projected DOS } \\
\text { (per atom) }\end{array}$ \\
\hline Total & 4.92 & $\mathrm{Ce}(3 \mathrm{~g})$ & 4.67 \\
Total for $s$ electrons & 0.06 & $\mathrm{Rh}(1 \mathrm{~b})$ & 0.17 \\
Total for $p$ electrons & 0.15 & $\mathrm{Rh}(2 \mathrm{c})$ & 0.19 \\
& & & 0.07 \\
Total for $d$ electrons & 0.36 & $\mathrm{~Pb}(3 \mathrm{f})$ & \\
& & &
\end{tabular}




\section{Figure captions}

Fig. 1. The hexagonal unit cell of $\mathrm{CeRhPb}$ and the coordination polyhedra of the Ce (a), Rh1 (b), Rh2 (c) and $\mathrm{Pb}(\mathrm{d})$ atoms.

Fig. 2. The Rh1- and Rh2-centered trigonal prisms in the crystal structure of $\mathrm{CeRhPb}$.

Fig. 3. The temperature variation of the molar magnetic susceptibility of $\mathrm{CeRhPb}$, measured in a field of $0.1 \mathrm{~T}$. The solid line is a fit described in the text. The inset shows the field variation of the magnetization in $\mathrm{CeRhPb}$ taken at $1.72 \mathrm{~K}$ with increasing (full circles) and decreasing (open circles) magnetic field strength.

Fig. 4. The total density of states (per f.u.) and the site contributions for DOS (per atom) (left panel), and the partial DOS (per f.u.) (right panel) in CeRhPb. The inset shows the contribution to the DOS near the Fermi level provided by the cerium $4 f$ electrons. 
Figure(s)

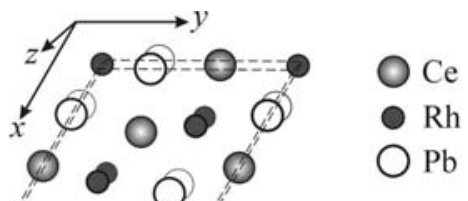

$=-0=-0$

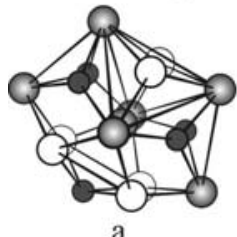

2

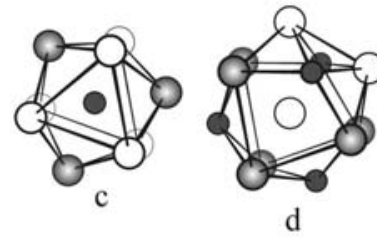


Figure(s)

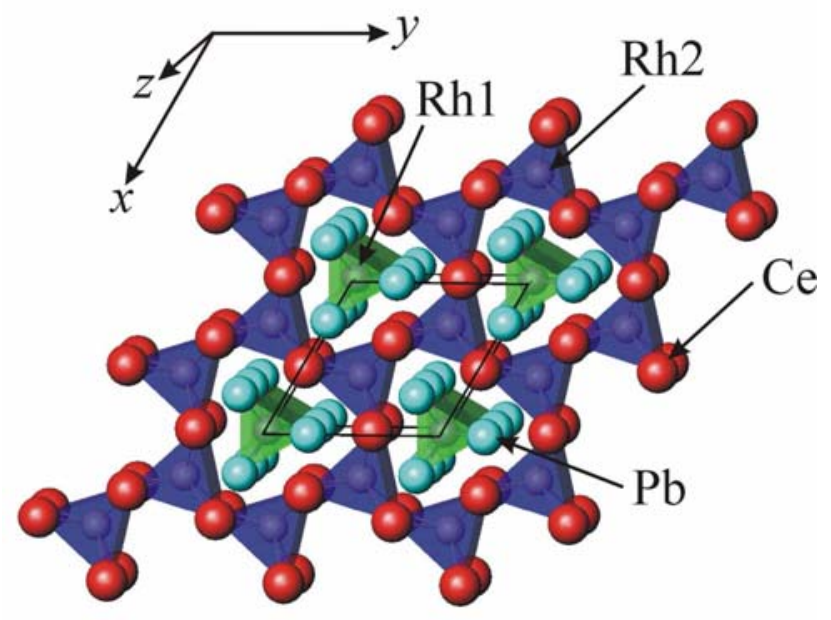


Figure(s)

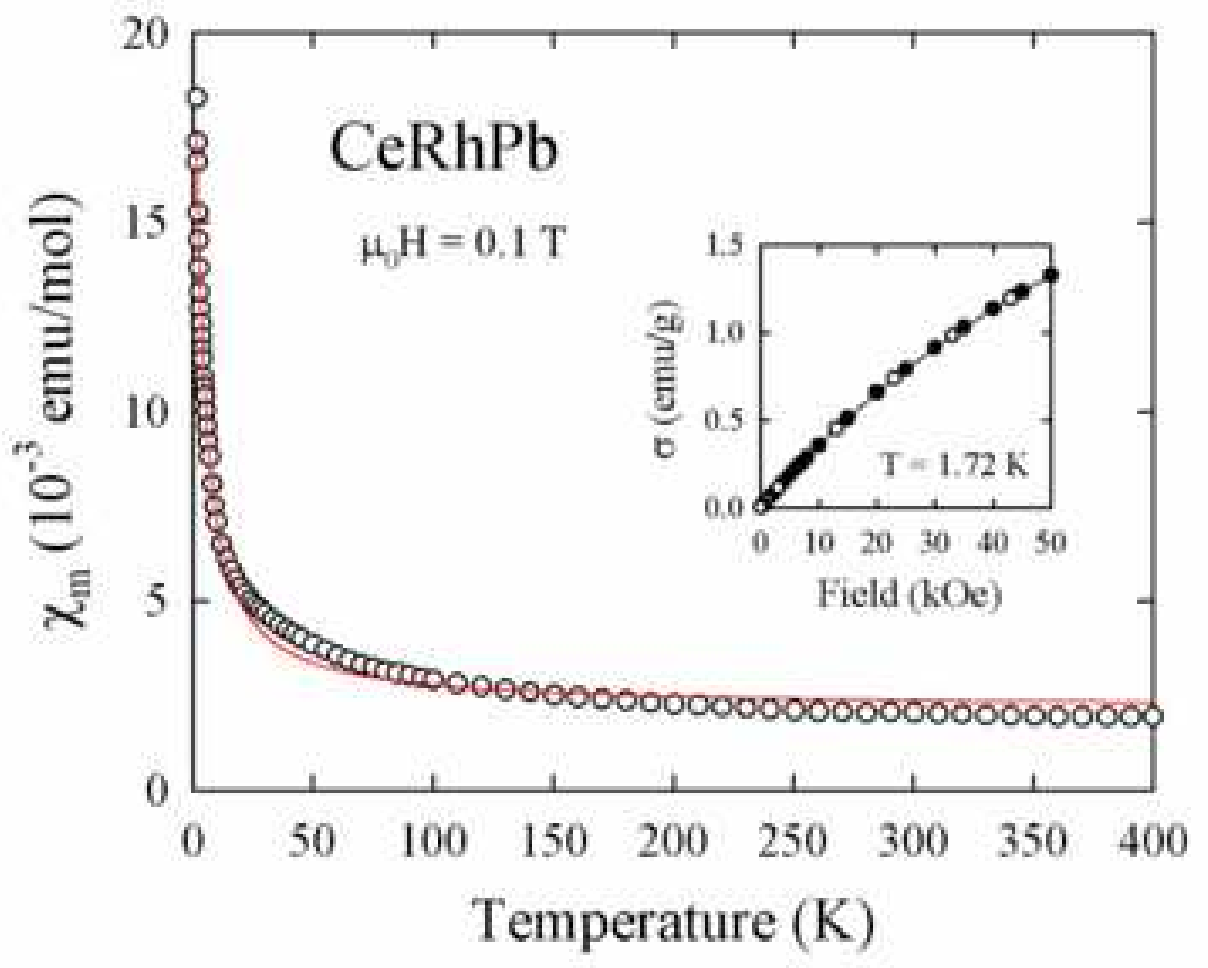




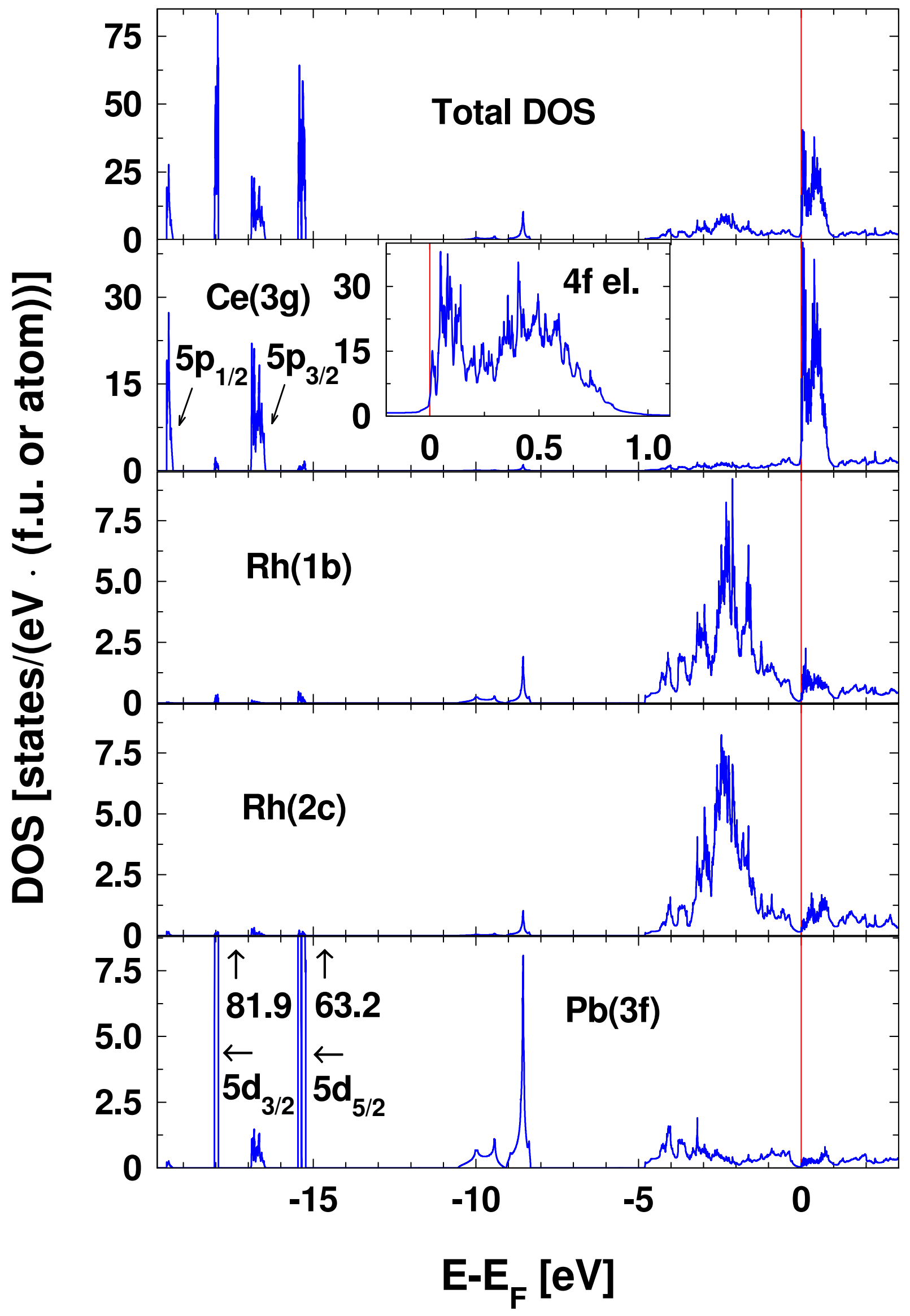




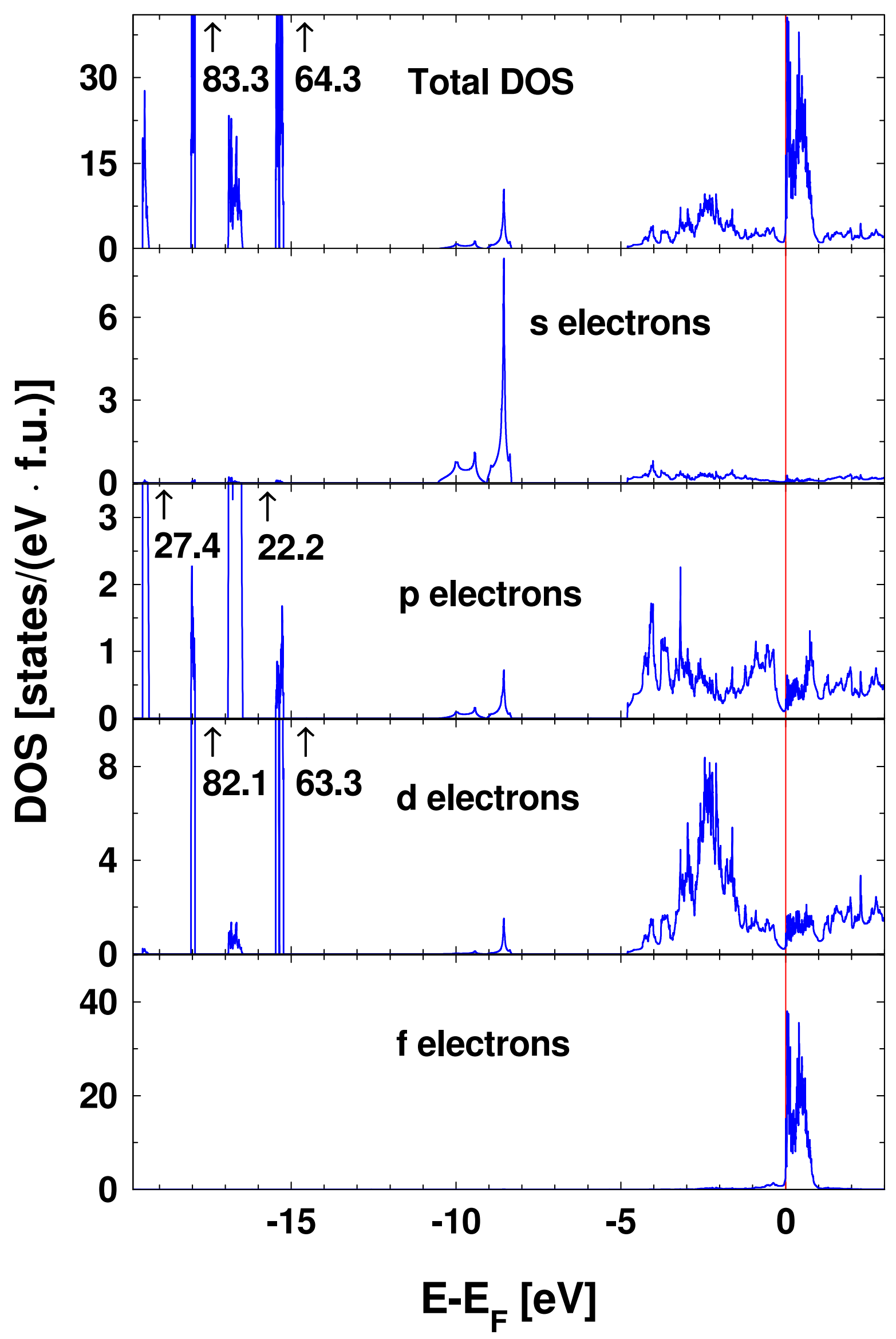

